\title{
HOW TO RESIST BRAMBLE'S ARGUMENTS AGAINST TEMPORAL WELL-BEING?
}

\author{
Tatjana Višak
}

\section{Introduction}

When I say that I am better off today than I was two weeks ago, I make a claim about my well-being at particular points in time, or at timespans that are shorter than my life as a whole. Thus, I talk about temporal wellbeing. Ben Bramble (2018) argues that there is no such thing as temporal well-being. He says it's okay for us to keep talking that way, but we should keep in mind that welfare at a time-say a day, a week or a year-doesn't really exist. Bramble suggests that most normal people wouldn't assume the existence of temporal welfare; it's mainly philosophers who make this mistake. I am highly suspicious about this empirical statement, since I hear non-philosophers talk about temporal well-being quite frequently. Bramble doesn't present any support for his empirical claim, and I'm not going to discuss it any further here. Instead, I'm going to evaluate and reject his ontological claim that there is no such thing as temporal welfare.

What, then, are Bramble's arguments against the existence of temporal welfare? Bramble presents the "normative significance argument," which I will dismiss in Section 2, and the "no credible theory argument," which I will reject in Section 3. I will conclude in Section 4 that Bramble's attempt at rejecting temporal welfare fails, and I will draw out some implications.

\section{Bramble's Argument from Normative Significance}

Bramble's first of two arguments against the existence of temporal welfare can be sketched as follows.

Bramble's Argument from Normative Significance

Premise 1: Genuine welfare is, per definition, ultimately morally significant.

Premise 2: While lifetime welfare is ultimately morally significant, temporal welfare is not.

Conclusion: Therefore, lifetime welfare is genuine welfare, but temporal welfare is not. 
The conclusion follows from the truth of both premises, but I think there are good reasons to deny the truth of each of the premises.

Let us consider premise 1 first. I agree with Bramble that welfare is ultimately normatively significant, but I take this to be a controversial substantive position and not a conceptual truth about welfare. Thus, I think that Bramble confuses a substantive normative position with a conceptual truth. According to Bramble, that welfare is per definition normatively significant best explains the fact that most people and some animals are genuine subjects of welfare, while other things that can also fare well or poorly in some sense, such as cars and trees, are not. Cars and trees, according to Bramble are not genuine subjects of welfare, because what happens to them is not of ultimate moral significance. I think that Bramble's explanation stands things on their heads. I wouldn't say that trees are not subjects of welfare because what happens to them is not ultimately normatively significant. I would rather say that what happens to trees is not ultimately normatively significant because they are not subjects of welfare. It is, of course, controversial whether trees are subjects of welfare. Similarly, and partly for this reason, it is controversial whether what happens to them is ultimately normatively significant. Those who, like me, hold that trees are not subjects of welfare, take, I think, a substantive position. They may accept a particular account of welfare, such as hedonism, preferentialism, or some objective list account and argue on that basis that trees are not subjects of welfare in this world, because they cannot realize the relevant goods in this world. Bramble $(2018,31)$ claims that showing that premise 1 of his argument is false "requires some other good way of explaining the difference between the sort of well-being that humans, cats, dolphins, etc., can have and the sort that cars, trees, etc., can have." He adds, "I, for one, cannot think of any other good way of explaining this difference."

Since there are such other ways, for instance on the basis of particular accounts of welfare, or even on the basis of particular conceptualizations of welfare, I think we need not assume that genuine welfare is normatively significant as a matter of conceptual truth. Many widely accepted accounts of welfare imply that normal adult humans are subjects of welfare, while cars are not. Furthermore, at least some conceptualizations of welfare imply that cars and trees cannot be subjects of welfare. For example, according to the positional analysis, cars and trees cannot be genuine subjects of welfare, because there is nothing it is like to be in their position. So, we do not need to appeal to the claim that welfare is per definition normatively significant to explain why cats are subjects of welfare while cars are not.

What is more, common conceptualizations of welfare do not entail the claim that welfare is normatively significant as a matter of conceptual truth. Conceptualizations of welfare aim at telling us what it means to say that something $p$ is good for some individual $S$. They do not make any claims about whether it makes outcomes better if $S$ possesses $p$ or about whether we have reason to make sure that $S$ possesses $p$. For example, the rational 
care analysis of welfare holds that ' $p$ is good for $S$ ' means 'if $S$ is worthy of care, then there is reason to desire $p$ out of care for $S$.' So, if we care for $S$, we have reason to desire $p$ for $S$. But this doesn't tell us that we should care for $S$ or that it is good simpliciter that $S$ possesses $p$. According to the locative analysis of welfare ' $p$ is good for $S$ ' means ' $p$ is good simpliciter and is located in $S$ 's life.' Again, this doesn't entail that we have reason to locate more of the things that are good simpliciter in people's lives, and it doesn't entail that outcomes in which more of the things that are good simplicitier are located in people's lives are better outcomes. According to the positional analysis of welfare ' $p$ is good for $S$ ' means ' $p$ contributes to the desirability of being in $S$ 's position.' I take it that ' $p$ is good for $S$ ' on this account means ' $p$ enhances the degree to which it is fitting to desire to be in $S$ 's position.' If I can enhance the degree to which it is fitting to desire to be in $S$ 's position, do I thereby, as a conceptual truth, make the outcome better? Do I, as a conceptual truth, do what I have reason to do? I don't think so. So, the positional analysis doesn't entail that we have reason to make it the case that more people occupy desirable positions or that outcomes in which more people occupy desirable positions are better. Lastly, according to the suitability analysis ' $p$ is good for $S$ ' means ' $p$ is suitable for $S$ in that it serves $S$ well.' This, again, doesn't entail that we have reason to make sure that individuals have the things that suit them well or that outcomes in which this is the case are better.

Let us now consider the second premise of Bramble's argument from normative significance. It claims that lifetime welfare but not temporal welfare is normatively significant. As Bramble explains, one way for $p$ to be normatively significant is making an outcome better in itself. That $p$ makes an outcome better in itself means that $p$ is intrinsically valuable. So, Bramble's second premise entails that only lifetime welfare but not temporal welfare is intrinsically valuable. Intrinsic value is contrasted to extrinsic value. The standard way of being extrinsically valuable is being instrumentally valuable. In as far as something is instrumentally valuable, it is not intrinsically valuable, but it is causally connected to intrinsic value. For example, if pleasure is intrinsically valuable, then eating ice cream is instrumentally valuable to the extent that it brings about pleasure.

An important issue for assessing the plausibility of Bramble's second premise concerns constitutive value. After all, lifetime welfare is intrinsically valuable, as Bramble admits. Furthermore, lifetime welfare may well be constituted by temporal welfare, in which case temporal welfare would have constitutive value. If $X$ has intrinsic value and is constituted by $\mathrm{Y}$, does $Y$ have intrinsic value in virtue of constituting $X$ ? This is, I think, a possible position. For example, if happiness has intrinsic value and consists in pleasure, then pleasure has intrinsic value in virtue of constituting happiness. If one conceives of the relationship between temporal well-being and lifetime well-being as constitutive in the sense that lifetime well-being amounts to the sum of temporal well-being, then Bramble's claim that 
changes in temporal well-being are not sufficient in themselves to affect the value of things simpliciter may well be false. All else equal, a change in temporal well-being amounts to a change in lifetime well-being. Therefore, that kind of constitutive value may well amount to an intrinsic value. So, it seems that Bramble's claim about the singular significance of lifetime well-being disregards the possibility of a constitutive relationship between temporal and lifetime welfare.

My rejection of premise 2 relies on the possible truth of the substantive view that lifetime welfare amounts to the sum of temporal welfare. Bramble argues against such a position, but I do not find his argument convincing. He says that even if, as a matter of fact, temporal welfare constitutes lifetime welfare, things could have been different and "in such an alternative scenario, it [temporal welfare] wouldn't necessarily have had any normative significance at all" (Bramble 2018, 31). It is not clear to me in what sense, according to Bramble, things could have been different and how that is supposed to be relevant for how things are in our world.

So, I reject Bramble's argument from moral significance by rejecting premise 1. I think that it is not the case that genuine welfare is per definition (i.e., as a conceptual truth) ultimately morally significant. I also reject premise 2 . I think that temporal welfare is ultimately normatively significant since it constitutes lifetime welfare. Note that rejecting only one of these premises would suffice to reject Bramble's argument from moral significance.

\section{Bramble's No Credible Theory Argument}

Bramble's second argument against the existence of temporal welfare is that no credible theory of welfare can account for it. The argument is simple and can be sketched as follows:

Bramble's no credible theory argument

Premise 1: If temporal welfare existed, then a credible theory of welfare would be able to account for it.

Premise 2: No credible theory of welfare can account for temporal welfare.

Conclusion 2: Therefore, there is no temporal welfare.

The argument is valid and I accept the first premise, but I am not convinced by Bramble's defense of the second premise.

Bramble argues in defense of the second premise that, given internalism about temporal welfare, no credible theory of welfare can account for temporal welfare. Internalism about temporal welfare is the view that one's welfare at some particular point in time must be determined solely by what happens at that point in time. Bramble, as I see it, makes the mistake of 
understanding internalism in a more demanding way. He takes it to imply that $S$ 's welfare at a particular point in time must be determined solely by the welfare level that $S$ would have at that point in time if only that particular point in time ever existed. Bramble then argues that one couldn't experience pleasure, satisfy desires, or realize achievements or friendship, if only one very brief point in time ever existed. After all, these goods require some longer stretch of time to be realized. That is true but, as I think, beside the point.

Assume that Tom enjoys a kiss with his lover that lasts ten seconds. Let us also grant that this kiss, obviously, does not fit within a timeframe that lasts only one split second. Thus, if only one split second ever existed, Tom couldn't have enjoyed that kiss. But does this mean that Tom didn't enjoy the kiss during every split second at which it actually took place? No! Tom in fact enjoyed the kiss during every split second at which it unfolded. Thus, hedonistic internalists who were interested in Tom's welfare at any particular split second should ask themselves what Tom's level of enjoyment actually was during every single split second while the kiss lasted. Assumingly, there is a fact of that matter about that. Let's assume that Tom's welfare was at +10 throughout the kiss. This means that it was at +10 at every split second during the kiss. So, I take it that Bramble's account of internalism is too strong. If we simply say that someone's momentary welfare needs to be determined by what happens at the moment, then hedonists, preferentialists, and proponents of objective list accounts of welfare can account for temporal welfare. After all, at least in our world that lasts longer than a split second, we can, at any given split second, be pleased to some degree, have a particular level of preference fulfillment, or realize achievement or friendship. Thus, I reject Bramble's second argument that no credible theory can account for temporal welfare. I think that all credible moral theories that Bramble mentions can account for temporal welfare.

\section{Conclusion}

Thus, Bramble's arguments against the existence of temporal welfare fail. Consider, again, his first argument:

Bramble's argument from normative significance

Premise 1: Genuine welfare is, per definition, ultimately morally significant.

Premise 2: While lifetime welfare is ultimately morally significant, temporal welfare is not.

Conclusion: Therefore, lifetime welfare is genuine welfare, but temporal welfare is not. 
We can reject premise 1. After all, since genuine welfare is not per definition normatively significant, its lacking normative significance would not preclude temporal welfare from being a form of genuine welfare. We can also reject premise 2 . This is because temporal welfare may not lack normative significance. After all, if we grant that lifetime welfare is normatively significant, as Bramble does, then there is a way for temporal welfare to be normatively significant as well. Temporal welfare may be intrinsically valuable because it constitutes lifetime welfare. Note that rejecting only one of these premises would be enough to reject the argument.

Now consider Bramble's second argument.

Bramble's no credible theory argument

Premise 1: If temporal welfare existed, then a credible theory of welfare would be able to account for it.

Premise 2: No credible theory of welfare can account for temporal welfare.

Conclusion 3: Therefore, there is no temporal welfare.

We can reject premise 2. Even if we go along with Bramble and accept internalism about temporal welfare- that is, the view that welfare at a time needs to be determined solely by what happens at that time-we need not accept that no credible theory can account for temporal welfare. We can reject Bramble's particular interpretation of internalism according to which $S$ 's welfare at time $t_{1}$ consists in the welfare that $S$ would have at $t_{1}$ if only $t_{1}$ ever existed.

Where does the rejection of Bramble's arguments leave us? Perhaps there are better arguments against the existence of temporal welfare. Unless and until someone presents these arguments, we can, I think, safely assume that temporal welfare exists. We need not, as Bramble proposes, ingeniously reinterpret claims that we make in daily life and that seem to be claims about temporal welfare, such as the claim that I mentioned in the beginning of this article.

Why would one want to deny the existence of temporal welfare? Some accounts of welfare seem unable to account for intrinsic temporal welfare, because these theories seem to assume that how well off someone is at some point in time depends on how the events at that point in time hang together with what happens at other points in time. For example, one might hold that $S$ 's pleasure at $t_{2}$ benefits $S$ if and only if and because $S$ has not derived pleasure from a similar experience before. Since Bramble (2015) seems to be drawn toward such a theory, I will call it "theory B." On the assumption that temporal welfare, provided that it exists, is intrinsic, theories of welfare that cannot account for intrinsic temporal welfare cannot account for temporal welfare. Assuming further that temporal welfare exists, it seems to be a weakness of an account of welfare that it cannot account for temporal welfare. 
The following argument can therefore be made:

Premise 1: If temporal welfare exists, all plausible accounts of welfare can account for temporal welfare.

Premise 2: If temporal welfare exists, it is intrinsic.

Premise 3: Theory B cannot account for intrinsic temporal welfare.

Conclusion 1: [from premise 2 and premise 3]: Theory B cannot account for temporal welfare.

Premise 4: Temporal welfare exists.

Conclusion 2: [from premise 1, conclusion 1 and premise 5]: Therefore, theory B is not a plausible account of welfare.

If you happen to be a proponent of theory $B$ and if you also happen to believe in premise 1 , premise 2 , and premise 3 , then the only way to avoid the devastating conclusion for your favored theory (i.e., C2) is denying premise 5. This might explain what motivated Bramble's arguments in his book.

If I am right that Bramble's arguments for rejecting premise 5 fail and that, more generally, rejecting premise 5 is unpromising, this leaves proponents of theory B with various alternative options. First, they can reject premise 1. Perhaps a plausible account of lifetime welfare need not also have a plausible story to tell about temporal welfare. Perhaps the relationship between temporal welfare and lifetime welfare is complicated, and solving one question can come without also immediately solving the other. Second, proponents of account of welfare B can reject premise 2. Perhaps temporal welfare is not intrinsic. Perhaps how well off I am at a time also depends on what happens at other times. Third, proponents of theory B can reject premise 3. Perhaps there is a plausible account of what it means that temporal welfare is intrinsic that does not preclude theory B from accounting for intrinsic temporal welfare. For example, if the good-making feature is experiencing a unique kind of pleasure, then there is a fact of the matter at any given time as to whether this is the case, even if we may not know that fact at that time. I think there are interesting discussions to be had about these issues. Even though I am not myself drawn toward theory B, I think it's too early to say whether or not some such theory can be defended. Rejecting temporal welfare is a daring attempt at defending it. Bramble's rejection of temporal welfare is not successful.

Tatjana Višak

Mannheim University, Germany E-mail: tatjana.visak@gmail.com 
References:

Bramble, Ben. 2015. “Consequentialism about Meaning in Life." Utilitas 27 (4): 445-459. Bramble, Ben. 2018. The Passing of Temporal Well-being. New York: Routledge. 